NOTE

\title{
First record of the at-sea swimming speed of a Pacific salmon during its oceanic migration
}

\author{
Hideji Tanaka ${ }^{1,2,7, *}$, Yasuhiko Naito ${ }^{1}$, Nancy D. Davis ${ }^{3}$, Shigehiko Urawa ${ }^{4}$, \\ Hiroshi Ueda ${ }^{5}$, Masa-aki Fukuwaka ${ }^{6}$ \\ ${ }^{1}$ National Institute of Polar Research, 1-9-10 Kaga, Itabashi, Tokyo 173-8515, Japan \\ ${ }^{2}$ Department of Social Informatics, Graduate School of Informatics, Kyoto University, Kyoto 606-8501, Japan \\ ${ }^{3}$ School of Aquatic and Fishery Sciences, University of Washington Seattle, Washington 98195-5020, USA \\ ${ }^{4}$ National Salmon Resources Center, Fisheries Agency of Japan, 2-2 Nakanoshima, Toyohira-ku, Sapporo 062-0922, Japan \\ ${ }^{5}$ Laboratory of Aquatic Bioresouces and Ecosystem, Section of Ecosystem Conservation, Field Science Center \\ for Northern Biosphere, Hokkaido University, Sapporo 060-0809, Japan \\ ${ }^{6}$ Hokkaido National Fisheries Research Institute, Fisheries Research Agency 116 Katsurakoi, Kushiro 085-0802, Japan \\ ${ }^{7}$ Present address: COE for Neo-Science and Natural History, Graduate School of Fisheries Sciences, Hokkaido University, \\ 041-8611 Hakodate, Japan
}

\begin{abstract}
The swimming behavior of the chum salmon Oncorhynchus keta was studied for $53 \mathrm{~d}$ of its $67 \mathrm{~d}$ oceanic migration from the central Bering Sea to the Japanese coast. We provide the first data on swimming speeds by a homing salmon, recorded at $5 \mathrm{~s}$ intervals by a fish-borne time-speed, depth, and temperature logger. Swimming speed rarely exceeded $1.0 \mathrm{~m} \mathrm{~s}^{-1}$, and horizontal swimming speed was $36.4 \pm 15.2 \mathrm{~km} \mathrm{~d}^{-1}$. Cumulative horizontal swimming distance was approximately $2500 \mathrm{~km}$, equivalent to $90 \%$ of the minimum distance between the release and recovery sites $(2760 \mathrm{~km})$. Swimming depth and speed peaked around dawn and dusk, and there was a smaller peak around midnight. The fish showed sequential up-and-down movement near the thermocline during daytime. Diurnal patterns of movement suggest that homing chum salmon spend a considerable time foraging, and the strategy is different between daytime and nighttime. Our findings indicate that over large distances of ocean, a homing salmon maintains a strong homeward orientation, but that passive transport by favorable water currents may help the migration.
\end{abstract}

KEY WORDS: Chum salmon · Oceanic migration · Swimming speed · Orientation · Time allocation • Foraging behavior

Resale or republication not permitted without written consent of the publisher

\section{INTRODUCTION}

Pacific salmon return to their natal rivers for spawning from high-seas foraging areas, which may be thousands of kilometers away. The mechanisms of oceanic orientation remain controversial; however, there is an impressive amount of evidence for the map and compass hypothesis (Hansen \& Quinn 1998). Swimming speed of homing salmon is a key factor in understanding their oceanic migration. If homing salmon are moving at their optimal cruising speed ( 0.9 to 1.0 body length $\mathrm{s}^{-1}$ ), which minimizes locomotion cost (Brett 1995), then the salmon would have to move along the shortest route from the open ocean to the spawning grounds (Quinn \& Groot 1984). If their orientation is less precise, then their swimming speed would have to exceed the optimal cruising speed for several weeks (Quinn \& Groot 1984) in order to achieve the ground speeds observed (40 to $60 \mathrm{~km} \mathrm{~d}^{-1}$ ) (Hartt 1966). From ultrasonic telemetry data collected over the span of several days, the ground speed of Pacific salmon has been estimated at 0.54 to $0.66 \mathrm{~m} \mathrm{~s}^{-1}$ during their open- 
ocean migration (Ogura \& Ishida 1995). Ground speed is defined as the net speed that results from summing the active swimming of the fish and the passive transport of the water currents. In coastal waters, the swimming speed (through the water) of sockeye salmon was estimated to be around $0.67 \mathrm{~m} \mathrm{~s}^{-1}$ from ultrasonic telemetry and current drogues (Quinn 1988). A more recent study, recorded by fish-borne speed data loggers, reported that the swimming speeds of free-ranging chum salmon in coastal waters ranged from 0.5 to $0.9 \mathrm{~m} \mathrm{~s}^{-1}$ (Tanaka et al. 2001). However, the actual swimming speed during the weeks of sustained effort required for the fish to return from distant high-seas locations has never been measured. Data on swimming speed may also play an important role in the analysis of homing behavior, because an 'optimal swimming speed', which may maximize locomotion cost of swimming or foraging efficiency, depends on fish behavior (Ware 1978). Vertical movement of homing chum salmon Oncorhynchus keta suggests a foraging behavior during the coastal phase of the migration (Ishida et al. 2001). Homing salmon may not be able to migrate and forage simultaneously. Consequently, they would have to be highly oriented during the time allocated to the homing migration.

\section{MATERIALS AND METHODS}

This study was conducted as part of a Japanese-US cooperative high-seas salmonid research cruise. In June-July 2000, we caught chum salmon by longline in the central Bering Sea. The healthy chum salmon were put into a recovery tank immediately after removal from the longline. Scales were collected for age determination and for the examination of scale patterns. Chum salmon with scale patterns typical of Japanese-origin fish (Ishida et al. 1989) were selected for tagging, because the high exploitation rate of these stocks maximized the likelihood of recovering the data logger. We selected 27 vigorous, maturing chum salmon $>600 \mathrm{~mm}$ (fork length), older than ocean age-. 3 (fish spent 3 winters at sea).

The data logger (Little Leonard, Model UWE-200 PDT: $42 \mathrm{~g}$ in air, $13 \mathrm{~g}$ in water, $20 \mathrm{~mm}$ in diameter, and $90 \mathrm{~mm}$ length), which records swimming speed (through the water), depth, and temperature (Tanaka et al. 2001), was attached externally in the dorsal musculature of the fish, anterior to the dorsal fin. The logger was fixed with a disk tag and a keplart thread ( $0.5 \mathrm{~mm}$ diameter; YGK YOZ-AMI) covered with a silicon tube, and supported by 2 titanium wires $(1.5 \mathrm{~mm}$ diameter). Tagged fish were released once they swam voluntarily. The logger sample rates were $5 \mathrm{sec}$ for depth and speed and 1 min for ambient temperature.
The speed sensor of the loggers consisted of a propeller rotation counter. In order to convert the rotation value of the propeller to actual swimming speed $\left(\mathrm{m} \mathrm{s}^{-1}\right)$, we examined the relationship between propeller revolutions per $5 \mathrm{~s}$ and the flow speed in a pool. The relationship was linear from 0.4 to $1.0 \mathrm{~m} \mathrm{~s}^{-1}$, and the coefficient of determination for each logger was $>0.96$. Rotation values were not converted to swimming speed when they were lower than the stall revolutions $\mathrm{s}^{-1}$, which was $0.4 \mathrm{~m} \mathrm{~s}^{-1}$. Therefore, speeds under $0.4 \mathrm{~m} \mathrm{~s}^{-1}$ were recorded as 0 .

After the retrieval of the logger from the field experiments, the data were downloaded to a computer and analyzed with Igor Pro software (Version 3.16J, WaveMatrics). The data were statistically analyzed using StatView software (Version 5.0, SAS Institute). We present all values as mean \pm SD unless noted otherwise, and use $p<0.05$ to indicate statistically significant differences. For analysis of behavioral parameters, we excluded swimming speed data from the statistics if more than $50 \%$ of the data were 0 .

Horizontal swimming speeds (through the water) of the fish can be defined as:

\section{Horizontal swimming speed $=$ (Swimming speed) $\cos \theta$}

where the swimming speed is the speed which the fish swims through the water along the longitudinal (tailto-head) body axis, and $\theta$ is the body angle of the longitudinal axis. In a previous study, fish body angle and swim depth of free-ranging chum salmon were determined by data loggers with acceleration sensors sampling at $1 \mathrm{~s}$ intervals (Tanaka et al. 2001). We reanalyzed those results using a $5 \mathrm{~s}$ interval, to find a relationship between the vertical rate $\left(\mathrm{m} \mathrm{s}^{-1}\right.$, rate of swimming depth change) and the body angle (degree) of chum salmon. There was a positive correlation between the vertical rate $(X)$ and the body angle $(Y)$ and the linear regression was $Y=-65.05 X\left(\mathrm{r}^{2}=0.81\right.$, $\mathrm{n}=3980, \mathrm{p}<0.001)$. We calculated the body angle using this equation and proceeded to the estimation of horizontal swimming speed using swimming speeds and cosine of the body angles. Cumulative horizontal swimming distance was defined as the sum of the horizontal swimming speeds $\left(\mathrm{m} \mathrm{s}^{-1}\right)$ by $5 \mathrm{~s}$, on the assumption that the tagged fish maintained a constant swimming speed during the sampling interval.

\section{RESULTS}

After $67 \mathrm{~d}$ at liberty, 1 chum salmon released in the central Bering Sea $\left(56^{\circ} 30^{\prime} \mathrm{N}, 179^{\circ} 00^{\prime} \mathrm{E}\right)$ on July 9, 2000 was caught in a set-net on the east coast of Hokkaido Island of Japan $\left(43^{\circ} 20^{\prime} \mathrm{N}, 145^{\circ} 46^{\prime} \mathrm{E}\right)$ on 
September 16, 2000 (Fig. 1). The fork length at the time of release was $685 \mathrm{~mm}$ and the fish was an ocean age-.4. The minimum distance over the ground between the release and recovery sites was $2760 \mathrm{~km}$. The recording period of depth and temperature was 52.9 d (22:47 h July 9 to 19:43 h August 31), and swimming speed data was recorded for $42.1 \mathrm{~d}$, because the propeller sensor became blocked with debris at 01:00 h on August 21. We did not get any information about the fate of the other 26 salmon and loggers.

The chum salmon usually stayed shallower than $50 \mathrm{~m}(10.2 \pm 12.5 \mathrm{~m}, \mathrm{n}=$ 911907), though the fish conducted 3 exceptionally deep dives (Fig. 2). Swimming speed through the water rarely exceeded $1.0 \mathrm{~m} \mathrm{~s}^{-1}$, and $31.3 \%$ of the total ( $\mathrm{n}=227577$ ) records were under $0.4 \mathrm{~m} \mathrm{~s}^{-1}$. For data over $0.4 \mathrm{~m} \mathrm{~s}^{-1}$, mean swimming speed was $0.62 \pm$ $0.12 \mathrm{~m} \mathrm{~s}^{-1}(\mathrm{n}=499780)$ with a maximum of $2.8 \mathrm{~m} \mathrm{~s}^{-1}$. Vertical rate was $0.06 \pm 0.09 \mathrm{~m} \mathrm{~s}^{-1}(\mathrm{n}=913630)$ and $83.6 \%$ of the total was confined within $\pm 0.1 \mathrm{~m} \mathrm{~s}^{-1}$, therefore, the fish body angle was usually maintained within $\pm 6.5^{\circ}$.

Horizontal swimming speed was $36.4 \pm 15.2 \mathrm{~km} \mathrm{~d}^{-1}$ (1.5 $\mathrm{km} \mathrm{h}^{-1}, \mathrm{n}=42$, from July 9 to August 20), though the salmon sometimes moved at speeds $<10 \mathrm{~km} \mathrm{~d}^{-1}$ during the initial $10 \mathrm{~d}$ (Fig. 3). If we exclude this lessactive period of the first $10 \mathrm{~d}$ from the analysis, mean horizontal speed was $42.3 \pm 11.5 \mathrm{~km} \mathrm{~d}^{-1}\left(1.8 \mathrm{~km} \mathrm{~h}^{-1}, \mathrm{n}=\right.$ 32, from July 20 to August 20). Cumulative horizontal swimming distance was $1534 \mathrm{~km}$ over $42 \mathrm{~d}$.

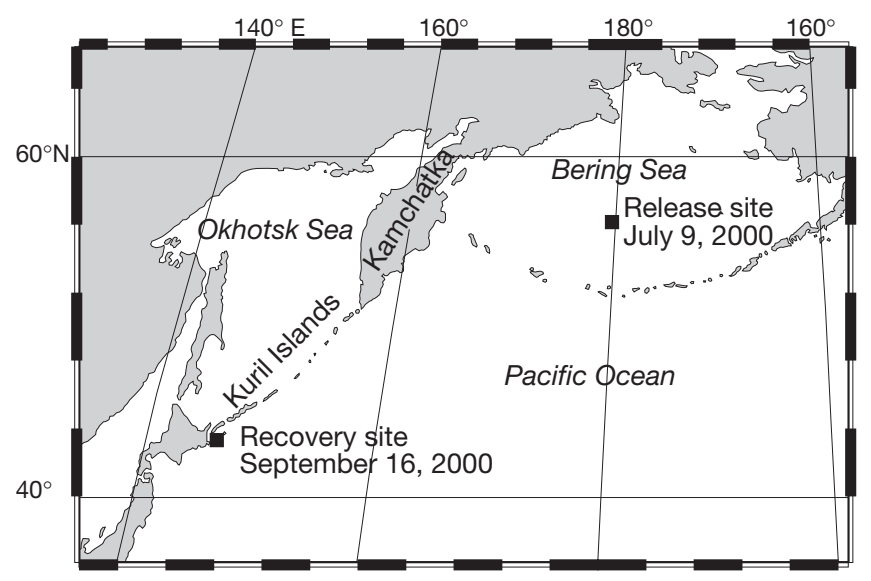

Fig. 1. Map indicating the release $\left(56^{\circ} 30^{\prime} \mathrm{N}, 179^{\circ} 00^{\prime} \mathrm{E}\right)$ and recovery $\left(43^{\circ} 20^{\prime} \mathrm{N}, 145^{\circ} 46^{\prime} \mathrm{E}\right)$ sites of a chum salmon carrying a data logger

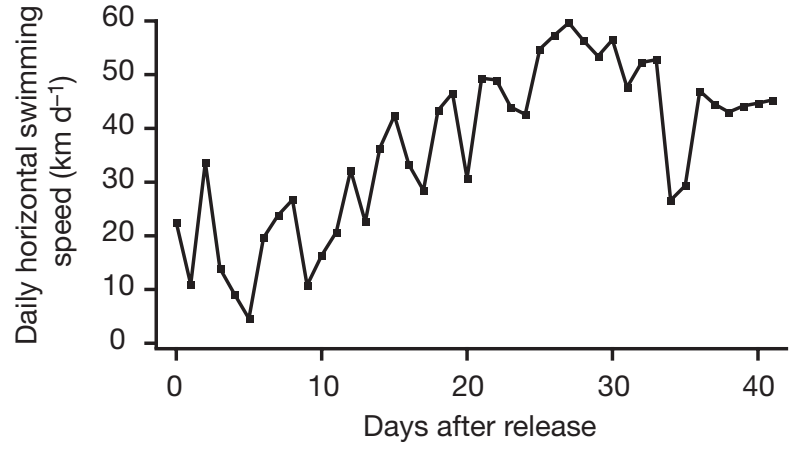

Fig. 3. Oncorhynchus keta. Daily mean horizontal (water) speed $\left(\mathrm{km} \mathrm{d}^{-1}\right)$ of a homing chum salmon. The horizontal speed was calculated from the swimming speed along the longitudinal body axis recorded by a data logger and body angle of the longitudinal axis estimated from the rate of change in depth of the fish. Lack of speed data $(<0.4 \mathrm{~m}$ $\mathrm{s}^{-1}$ or intermissions due to debris blocking the sensor) were regarded as 0

The hourly average of both depth ( $\mathrm{n}=50$ to $52 \mathrm{~d}$ ) and speed ( $\mathrm{n}=22$ to $35 \mathrm{~d}$ ) peaked around dawn and sunset with a smaller peak around midnight (Fig. 4). Swimming speeds during the peak in activity at dawn and sunset (05:00 to $08: 00 \mathrm{~h}, 0.61$ to $0.65 \mathrm{~m} \mathrm{~s}^{-1}$; and 14:00 to $18: 00 \mathrm{~h}, 0.61$ to $0.64 \mathrm{~m} \mathrm{~s}^{-1}$ ) were significantly faster than during the trough in activity at 03:00 and 20:00 $\mathrm{h}$ (0.48 $\mathrm{m} \mathrm{s}^{-1}$; Bonferroni post hoc test, $\left.\mathrm{p}<0.0001\right)$. The fish swam significantly deeper at sunset $(17: 00 \mathrm{~h}$, $13.8 \mathrm{~m}$; and $18: 00 \mathrm{~h}, 13.3 \mathrm{~m})$ than at $02: 00 \mathrm{~h}(5.9 \mathrm{~m}$; Bonferroni post hoc test, $\mathrm{p}<0.0001)$, while there were no significant differences among other times of day. Hourly averages of swimming speed had a significant 


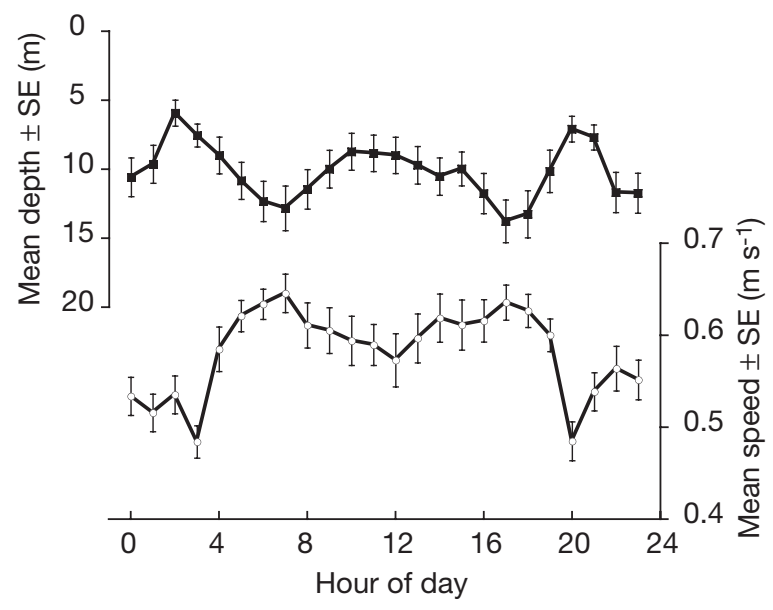

Fig. 4. Oncorhynchus keta. Hourly mean swimming depth (n $=50$ to $52 \mathrm{~d}$ ) and hourly mean swimming speed ( $\mathrm{n}=22$ to $35 \mathrm{~d}$ ) for a chum salmon during its open-ocean homing migration

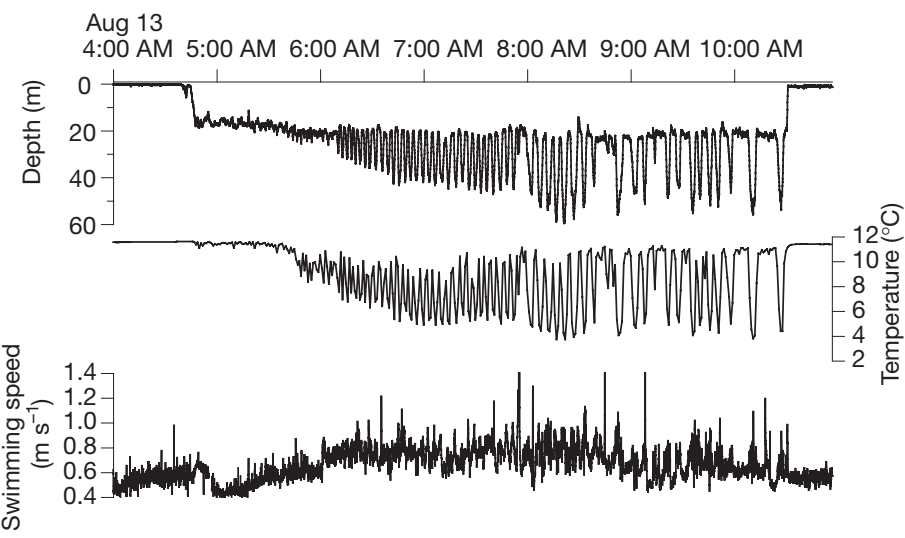

Fig. 5. Oncorhynchus keta. A $7 \mathrm{~h}$ excerpt of time-depth, temperature, and swimming speed data for a chum salmon showing a typical pattern of repeated v-shaped vertical movements ('diving bouts') in the vicinity of the thermocline

positive correlation with depth (Kendall's $t=0.24, \mathrm{z}=$ 9.497, $\mathrm{p}<0.0001, \mathrm{n}=693$ ).

Generally, the chum salmon conducted sequential vertical dives during the daytime. A typical pattern of vertical movement is shown in Fig. 5. It shifted swimming depth from the surface to the vicinity of the thermocline, and proceeded to make a series of v-shaped dives. To characterize this diving behavior, we defined steady vertical travel (descent or ascent) as $>10 \mathrm{~m}$, an intermission between steady vertical travels as $<10 \mathrm{~min}$, and a 'dive bout' as $>20$ steady vertical travels. The salmon conducted dive bouts 25 times in $16 \mathrm{~d}$ during the recording period (Fig. 6). Lower and upper depth of the dive bout, which was calculated by the mean values of the deepest points of the $\mathrm{v}$-shaped dive and the depths in a non-dive phase, was $35.7 \pm 8.7$ and $5.6 \pm 1.3 \mathrm{~m}$, respectively. The first dive bout occurred $13 \mathrm{~d}$ after release. The duration of a dive bout was $152 \pm 96.4 \mathrm{~min}$. Dive bouts occurred only during the daytime (04:00 to 20:00 h). The chum salmon conducted $\mathrm{v}$-shaped dives $21.8 \pm 6.8$ times in a dive bout at the rate of $8.6 \pm 2.7$ times $\mathrm{h}^{-1}$. The duration of the $\mathrm{v}$ shaped dive was $5.1 \pm 2.8 \mathrm{~min}$ and the interval between dives was $1.4 \pm 1.7 \mathrm{~min}(\mathrm{n}=569)$. The fish swam at $0.70 \pm 0.10 \mathrm{~m} \mathrm{~s}^{-1}(\mathrm{n}=543)$ around the deepest depth in v-shaped dives, which was significantly faster than swimming speeds between dives $(0.67 \pm 0.13 \mathrm{~m}$ $\mathrm{s}^{-1}, \mathrm{n}=432$ ) (Wilcoxon signed-rank test, $\mathrm{p}<0.0001$ ). The difference in ambient water temperature that the fish experienced within a dive was $4.5 \pm 2.0^{\circ} \mathrm{C}$ (maximum $=10.4^{\circ} \mathrm{C}, \mathrm{n}=569$ ).

\section{DISCUSSION}

A homing chum salmon in the open ocean swam at relatively constant speeds through the water of approximately 0.9 to 1.0 body length $\mathrm{s}^{-1}$ for about two-thirds of the data record, and the fish swam at $<0.4 \mathrm{~m} \mathrm{~s}^{-1}$ during about one-third of the data record. This result is compatible with predicted optimal swimming speeds through the water, which minimize locomotion cost (Brett 1995).

The chum salmon swam a cumulative horizontal swimming distance of approximately $1500 \mathrm{~km}$ by the end of the recording period, although this value was underestimated due to the removal of low-speed data. If the fish continued to swim at the average

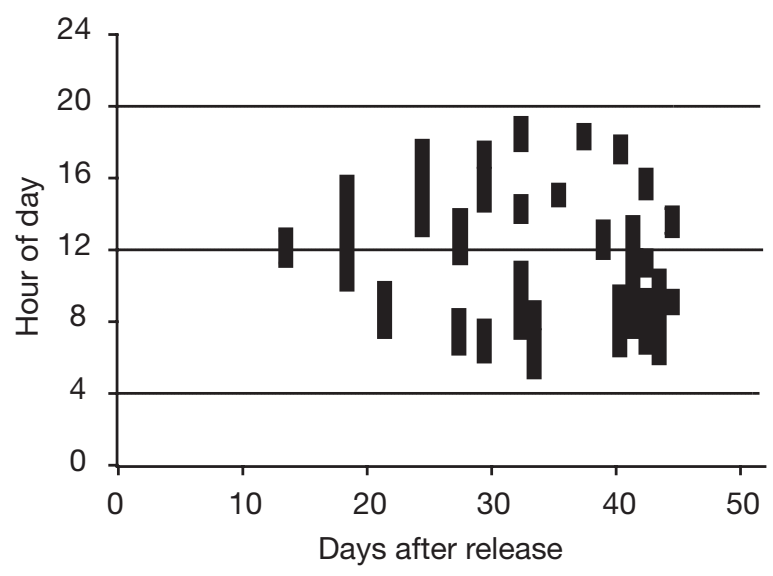

Fig. 6. Oncorhynchus keta. Diurnal pattern and duration of diving bouts by a chum salmon during its open-ocean homing migration. Each rectangle indicates the duration of the diving bout (from start hour to end hour). In total, 26 diving bouts were detected throughout the recording period 
speed (36.4 $\mathrm{km} \mathrm{d}^{-1}$ ) after the logger finished its recording, the total horizontal swimming distance would be $2440 \mathrm{~km}$. According to high-seas tag recapture data of chum salmon, the mean ground speed of a maturing adult is $38.5 \mathrm{~km} \mathrm{~d}^{-1}$ off eastern Kamchatka in July ( $\mathrm{n}=$ $10)$, around $30 \mathrm{~km} \mathrm{~d}^{-1}$ off the Kuril Islands $(\mathrm{n}=2)$ and Japanese coast $(\mathrm{n}=73)$ in August, and $35.6 \mathrm{~km} \mathrm{~d}^{-1}$ off the Japanese coast in September $(n=73)$ (Ogura 1994). The present results are generally in accord with the values estimated from tagging, although we calculated speed through the water, not ground speed. The reduction in swimming speed during the initial week may have been a response to tagging trauma (Walker et al. 2000). If we adopted the average swimming speed excluding data from the initial $10 \mathrm{~d}(42.3 \mathrm{~km}$ $\mathrm{d}^{-1}$, the total cumulative horizontal swimming distance would be $2580 \mathrm{~km}$. This value is equivalent to about $90 \%$ of the minimum distance between the release and recovery sites $(2760 \mathrm{~km})$, at a ground speed of $41.2 \mathrm{~km} \mathrm{~d}^{-1}$. These findings suggest that the chum salmon could not cover the entire distance from the central Bering Sea to the Japanese coast without passive transport. The East Kamchatka Current flows south along the east coast of Kamchatka and the Kuril Islands. Yonemori (1975) suggested a relation between this current and the movement of chum salmon; however, the return migration pattern of chum salmon cannot be explained simply on the basis of ocean currents (Ogura 1994). The mechanism of how homing chum salmon use passive transport by the ocean currents is unclear, and warrants examination.

Daytime dive bouts through the thermocline may be caused by the requirements of prey capture and thermoregulation. In the central Bering Sea, chum salmon consume fish, pteropods, and gelatinous zooplankton during the daytime (Davis et al. 2000). The peak biomass of micronekton and gelatinous plankton is in the upper $20 \mathrm{~m}$ during the night, and these organisms move deeper in the water column during the day (Nishikawa et al. 2001). Vertical migrations of prey species may make the energetic cost of foraging higher in the day than in the night. Examination of chum salmon stomach contents suggests that they shift their behavior from feeding predominantly on gelatinous zooplankton during the night to high-caloric fish during the day (Davis et al. 2000). Our results suggest that chum salmon may be diving below the thermocline in order to consume fish that leave surface waters during that time of day. The salmon's swimming speed accelerated during these periods (Figs. 4 \& 5). This is consistent with the assumption that optimal swimming speed of foraging fish, which maximizes foraging success, is slightly higher than the optimal cruising speed (Ware 1978). The acceleration of swimming speed also provides evidence that chum salmon are foraging for fishes, which are faster-moving prey than zooplankton. If $\mathrm{v}$-shaped dives are foraging behavior, then chum salmon should make long dives when a foraging patch is good in quality (Mori et al. 2002). However, during dive bouts, the salmon made repeated multiple dives, which lasted less than half an hour. The chum salmon's return to warmer water above the thermocline may help it to maintain a higher body temperature, which supports higher consumption and activity rates (Davis et al. 1998, Walker et al. 2000). Therefore, the dive duration of $\mathrm{v}$-shaped dives may be affected by the trade-off between foraging efficiency and the body temperature of the fish. Although the chum salmon moved to greater depths around midnight, it never engaged in diving bouts during the nighttime. At midnight, the mean depth increased from approximately 6 to $11 \mathrm{~m}$, with an accompanying slight increase in swimming speed. At this time, chum salmon can feed on dense patches of slow-moving gelatinous zooplankton with less foraging effort. The fish may adopt 2 different prey-capture strategies: active foraging during the daytime, and low-cost feeding during nighttime. Our dive data indicate that chum salmon spend a considerable amount of time feeding throughout their oceanic migration. Although our study was limited by the recovery of only 1 chum salmon, our findings emphasize that homing salmon are strongly oriented in a homeward direction, and that passive transport by water currents may play a significant role.

Acknowledgements. The authors would like to thank the captains, officers, and crew of RV 'Wakatake maru', K. Yamaya, $\mathrm{S}$. Tsuchiya and several students for their help in releasing tagged fish, and to the individual who recovered the fish carrying the data logger. This work was supported by the Promotion Program for International Resources Surveys from the Fisheries Agency of Japan, the Grant-in-Aid from the Japan Society for the Promotion of Science (11460093), and the MEXT Grant-in-Aid for the 21st Century COE Program 'NeoScience of Natural History' Program at Hokkaido University. Funding for N.D. Davis was provided by the Auke Bay Laboratory, Alaska Fisheries Science Center, NOAA Fisheries (NOAA Contract No. 50ABNF-0-00008). We gratefully acknowledge helpful discussions with N. Arai and T. Kameda on the analysis of temperature data, and we are also grateful to T. P. Quinn and 3 anonymous referees for providing constructive comments on the manuscript.

\section{LITERATURE CITED}

Brett JR (1995) Energetics. In: Groot C, Margolis L, Clark WC (eds) Physiological ecology of Pacific salmon. UBC Press, Vancouver, p 1-68

Davis ND, Aydin KY, Ishida Y (2000) Diel catches and food habits of sockeye, pink, and chum salmon in the central Bering Sea in summer. N Pac Anadr Fish Comm Bull 2: 99-109

Davis ND, Myers KW, Ishida Y (1998) Caloric value of highseas salmon prey organisms and simulated salmon ocean 
growth and prey consumption. N Pac Anadr Fish Comm Bull 1:146-162

Hansen LP, Quinn TP (1998) The marine phase of the Atlantic salmon (Salmo salar) life cycle, with comparisons to Pacific salmon. Can J Fish Aquat Sci 55:104-118

Hartt AC (1966) Migrations of salmon in the North Pacific Ocean and Bering Sea by seining and tagging, 1959-1960. Int North Pac Fish Comm Bull 19:141

Ishida Y, Ito S, Takagi K (1989) Stock identification of chum salmon Oncorhynchus keta from their maturity and scale characters. Nippon Suisan Gakkaishi 55:651-656

Ishida Y, Yano A, Ban M, Ogura M (2001) Vertical movement of a chum salmon Oncorhynchus keta in the western North Pacific Ocean as determined by a depth-recording archival tag. Fish Sci 67:1030-1035

Mori Y, Takahashi A, Mehlum F, Watanuki Y (2002) An application of optimal diving models to diving behavior of Brünnich's guillemots. Anim Behav 64:739-745

Nishikawa J, Nishida S, Moku M, Hidaka K, Kawaguchi K (2001) Biomass, abundance, and vertical distribution of micronekton and large gelatinous zooplankton in the subarctic Pacific and the Bering Sea during the summer of 1997. J Oceanogr 57:361-375

Ogura M (1994) Migratory behavior of Pacific salmon (Oncorhynchus spp.) in the open sea. Bull Nat Res Inst Far

Editorial responsibility: Otto Kinne (Editor-in-Chief), Oldendorf/Luhe, Germany
Seas Fish 31:1-139

Ogura M, Ishida Y (1995) Homing behavior and vertical movements of species of Pacific salmon (Oncorhynchus spp.) in the central Bering Sea. Can J Fish Aqua Sci 52: 532-540

Quinn TP (1988) Estimated swimming speeds of migrating adult sockeye salmon. Can J Zool 66:2160-2163

Quinn TP, Groot C (1984) Pacific salmon (Oncorhynchus) migrations: orientation versus random movement. Can J Fish Aquat Sci 41:1319-1324

Tanaka H, Takagi Y, Naito Y (2001) Swimming speeds and buoyancy compensation of migrating adult chum salmon Oncorhynchus keta revealed by speed-depth-acceleration data logger. J Exp Biol 204:3895-3904

Walker RV, Myers KW, Davis ND, Aydin KY, Friedland KD, Carlson HR, Boehlert GW, Urawa S, Ueno Y, Anma G (2000) Diurnal variation in thermal environment experienced by salmonids in the North Pacific as indicated by data storage tags. Fish Oceanogr 9:171-186

Ware DM (1978) Bioenergetics of pelagic fish: theoretical change in swimming speed and ration with body size. J Fish Res Board Can 35:220-228

Yonemori T (1975) A trial analysis of the results obtained from tagging on chum salmon originating from Hokkaido. Int North Pac Fish Comm Bull 32:130-161

Submitted: May 25, 2004; Accepted: December 30, 2004 Proofs received from author(s): April 15, 2005 